\title{
Studies on Intestinal Absorption of Sfericase Produced by Bacillus sphaericus
}

\author{
Michio Ninobe, Yuji Hitomi and Setsuro FuJI \\ Division of Regulation of Macromolecular Function, \\ Institute for Protein Research, Osaka University, \\ Suita, Osaka 565, Japan \\ Received May 26, 1980
}

\begin{abstract}
The intestinal absorption of sfericase, a microbial serine proteinase producd by Bacillus sphaericus, was studied using acetyl-L-tyrosine $\alpha$-naphthyl ester (ATNE) as substrate. This substrate was highly susceptible to sfericase, and with it, the minimum detectable concentration of sfericase was about $0.004 \mu \mathrm{g}$.

In experiments on intestinal absorption, sodium dodecylsulfate was added to the assay system at a final concentration of $0.1 \%$, since at this concentration it inhibited more than $90 \%$ of the endogenous ATNE-hydrolytic activity of rabbit serum but only about $50 \%$ of that of sfericase, and thus permitted measurement of sfericase concentration in blood.

The concentration of sfericase in blood was maximal $2 \mathrm{hr}$ after direct injection of sfericase powder into the intestinal tract, and absorption at this time amounted to $0.07 \%$ of the injected dose. On the other hand, the concentration in blood was maximal $3 \mathrm{hr}$ after oral administration of entericcoated particles of sfericase, and the absorption amounted to $0.003 \%$. These results suggest that sfericase is absorbed in active form.
\end{abstract}

Accumulating evidence suggests that small amounts of protein are absorbed in an intact or only slightly degraded form from the intestinal lumen. Kabacoff et al. reported intestinal absorption of chymotrypsin in rabbits, detected by its ATEE hydrolytic activity); Martin et al. reported the intestinal absorption of ${ }^{131}$ I-trypsin in rats ${ }^{2)}$; and Smyth et al. observed absorption of bromelain labeled with a fluorescent substance from enteric-coated tablets in rats. ${ }^{3)}$ However, results with labeled proteins do not provide direct evidence that intact proteins are absorbed, because the absorbed radioactivity is not necessarily that of intact proteins: it may be that of labeled amino acids in small peptides, or of labeled amino acids incorporated into

Abbreviations: ATNE, acetyl-L-tyrosine $\alpha$-naphthyl ester; TLNE, tosyl-L-lysine $\alpha$-naphthyl ester; AGLNE, acetylglycyl-L-lysine $\alpha$-naphthyl ester; ATEE, acetyl-Ltyrosine ethyl ester; TLME, tosyl-L-lysine methyl ester; AGLME, acetylglycyl-L-lysine methyl ester; TAME, tosylL-arginine methyl ester; SDS, sodium dodecylsulfate; DMSO, dimethylsulfoxide. other proteins after absorption. For unequivocal proof that enzymes are absorbed intact from the intestine, their absorption must be demonstrated in terms of enzymatic activity.

Murachi et al. reported that acetylated egg white lysozyme was absorbed better than the intact enzyme when injected into the intestine of rabbits. ${ }^{4)}$ Isselbacher et al. observed the absorption of bovine serum albumin from rat duodenum. ${ }^{5)}$ Moreover, using elastase antibody, Katayama et al. detected the intestinal absorption of elastase. ${ }^{6)}$ However, immunological assay gives no information on whether the absorbed enzyme is active or inactive. Previously, we reported that $\alpha$ naphthyl esters of acetyl-L-tyrosine, tosyl-Llysine and acetylglycyl-L-lysine were very susceptible to various trypsin- and chymotrypsinlike enzymes. ${ }^{7)}$ This paper reports studies on the intestinal absorption of sfericase, a microbial serine proteinase found and purified from Bacillus sphaericus by Yoshida et al. $\left.{ }^{8}\right) \mathrm{We}$ demonstrated that sfericase was absorbed in an intact form from the intestine by measuring 
ATNE hydrolytic activity in the serum.

\section{MATERIALS AND METHODS}

Materials. Acetyl-L-tyrosine ethyl ester (ATEE), tosylL-lysine methyl ester (TLME), acetyl-glycyl-L-lysine methyl ester (AGLME) and tosyl-L-arginine methyl ester (TAME) were obtained from the Protein Research Foundation, Osaka, Japan. Acetyl-L-tyrosine $\alpha$-naphthyl ester (ATNE), tosyl-L-lysine $\alpha$-naphthyl ester (TLNE) and acetyl-glycyl-L-lysine $\alpha$-naphthyl ester (AGLNE) were prepared in the Research Laboratories of Torii \& Co., Ltd., Tokyo, Japan. Highly purified sfericase and entericcoated particles of the enzyme were kindly supplied from the Research Laboratories of Meiji Seika Co., Yokohama, Japan.

Enzyme assay. Sfericase was dissolved in $50 \mathrm{~mm}$ sodium phosphate buffer (pH 7.4). AGLME, TLME, TAME and ATEE were dissolved in distilled water at a concentration of $10 \mu \mathrm{mol}$ per $0.4 \mathrm{ml}$; TLNE was dissolved at a concentration of $0.5 \mu \mathrm{mol}$ per $0.5 \mathrm{ml}$ in distilled water containing $4 \%$ dimethylsulfoxide (DMSO); ATNE was dissolved at a concentration of $0.5 \mu \mathrm{mol}$ per $0.5 \mathrm{ml}$ in distilled water containing $10 \%$ DMSO; AGLNE was dissolved at a concentration of $0.125 \mu \mathrm{mol}$ per $0.5 \mathrm{ml}$ in distilled water. Esterolytic activities on the methyl and ethyl esters were determined by the method of Hesterin as modified by Roberts after incubation with the enzyme solution in a total volume of $1 \mathrm{ml}$ at $37^{\circ} \mathrm{C}$ for $30 \mathrm{~min} .^{9)}$ Esterolytic activities on $\alpha$-naphthyl esters were determined as follows. The complete medium in a final volume of $1 \mathrm{ml}$ consisted of $0.5 \mathrm{ml}$ of substrate solution containing $0.5 \mu \mathrm{mol}$ of ATNE or TLNE, or $0.125 \mu \mathrm{mol}$ of AGLNE, and $0.5 \mathrm{ml}$ of enzyme solution. Incubation was carried out in duplicate at $25^{\circ} \mathrm{C}$ for $30 \mathrm{~min}$. As a blank, a mixture of $50 \mathrm{~mm}$ sodium phosphate buffer $(\mathrm{pH} 7.4)$ and substrate solution was incubated at $25^{\circ} \mathrm{C}$ for $30 \mathrm{~min}$. After incubation, $0.1 \mathrm{ml}$ of $1 \%$ Fast Violet B salt solution (aqueous solution) was rapidly added. The mixtures were stood at $0^{\circ} \mathrm{C}$ for $30 \mathrm{~min}$, and then $1 \mathrm{ml}$ of acetic acid was added and the intensity of color developed in the diazocoupling reaction was estimated from the absorbancy at $515 \mathrm{~nm}$. Enzyme alone gave no color in the diazo-coupling reaction. Caseinolytic activity was determined by the method of Lowry et al.$^{10)}$ after incubation for $30 \mathrm{~min}$ at $37^{\circ} \mathrm{C}$, as described in the previous report. ${ }^{11}$

Inhibitory effect of SDS. Mixtures of $0.2 \mathrm{ml}$ of $50 \mathrm{~mm}$ sodium phosphate buffer $(\mathrm{pH}$ 7.4) containing SDS at various concentrations and $0.2 \mathrm{ml}$ of sfericase of appropriate concentration in buffer or $0.1 \mathrm{ml}$ of rabbit serum diluted with physiological saline were made up to $0.5 \mathrm{ml}$ with buffer and incubated at $37^{\circ} \mathrm{C}$ for $10 \mathrm{~min}$. Then $0.5 \mathrm{ml}$ of ATNE solution was added and the mixture was incubated for an additional $30 \mathrm{~min}$ at $25^{\circ} \mathrm{C}$. The $\alpha$ - naphthol released by the enzyme reaction was estimated as described above. In the control mixture $50 \mathrm{~mm}$ sodium phosphate buffer ( $\mathrm{pH}$ 7.4) was used in place of SDS. In experiments on the inhibitory effect of SDS on a mixture of sfericase and rabbit serum, mixtures of $0.2 \mathrm{ml}$ of $0.1 \%$ SDS solution, $0.1 \mathrm{ml}$ of enzyme solutions containing various concentrations of sfericase, $0.1 \mathrm{ml}$ of rabbit serum and $50 \mathrm{~mm}$ sodium phosphate buffer $(\mathrm{pH}$ 7.4), were incubated at $37^{\circ} \mathrm{C}$ for $10 \mathrm{~min}$. Then $0.5 \mathrm{ml}$ of ATNE solution was added and incubation was continued at $25^{\circ} \mathrm{C}$ for $30 \mathrm{~min}$. The $\alpha$-naphthol released by the enzyme reaction was estimated as described above. SDS or rabbit serum was omitted from the control mixtures.

Intestinal absorption of sfericase injected directly into the intestine. Male albino rabbits, weighing $2500 \sim 3000 \mathrm{~g}$, were starved for $24 \mathrm{hr}$ and then anesthetized with amobarbital. The abdomen was opened by a mid-line incision, the pylorus was ligated, and $200 \mathrm{mg}$ of sfericase in $10 \mathrm{ml}$ of saline was injected into the intestinal lumen. Blood samples $(2 \mathrm{ml})$ were taken from the ear vein at appropriate times. The blood was allowed to clot, and the resultant serum $(0.1 \mathrm{ml}$ of 10 -fold diluted serum) was assayed for ATNE hydrolytic activity in the presence of $0.1 \%$ SDS.

Intestinal absorption of enteric-coated particles of sfericase administered orally. Male albino rabbits, weighing $2500 \sim 3000 \mathrm{~g}$, were starved for $24 \mathrm{hr}$ and then $1 \mathrm{~g}$ of enteric-coated particles of sericase was administered by stomach tube. At appropriate times blood samples were taken from the ear vein and ATNE hydrolytic activity was measured as described above, using $0.1 \mathrm{ml}$ of undiluted serum.

Calculation of the percentage absorption of sfericase. The total amount of sfericase in the blood was calculated assuming that whole blood constitutes one thirteenth of the body weight. ${ }^{12)}$ The percentage absorption was then calculated from the ratio of total sfericase activity in the blood to that administered. Sfericase activity was measured in the presence of $0.1 \% \mathrm{SDS}$.

\section{RESULTS}

\section{Substrate specificity of sfericase}

Figure 1 shows the activities of sfericase on three substrates. The highest activity was observed with ATNE, the minimum detectable amount of enzyme (giving absorbancy of 0.1 with ATNE) being about $0.004 \mu \mathrm{g}$ (Fig. 1a). The minimum detectable amounts of sfericase with TLNE, AGLNE, ATEE, TLME, AGLME, TAME and casein were about 0.8 , $0.9,0.25,5.8,0.45,11.5$ and $0.2 \mu \mathrm{g}$, re- 

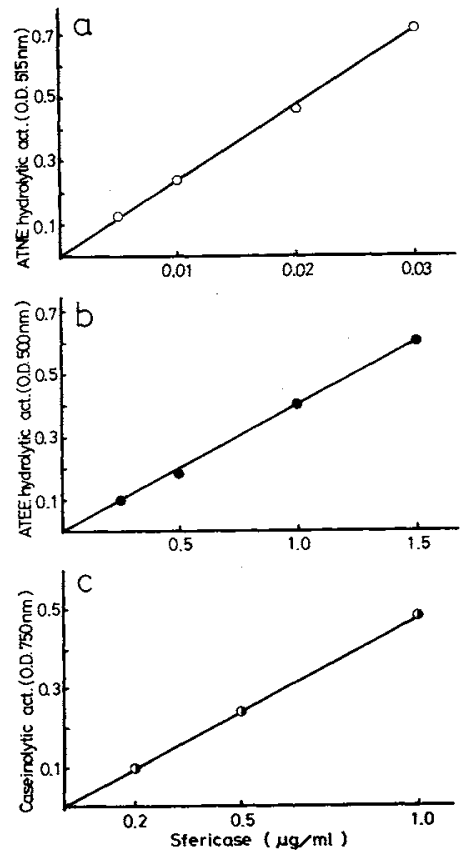

FIG. 1. Hydrolysis of ATNE, ATEE and Casein by Sfericase.

Assays were carried out as described in MATERIALS AND Methods. a, ATNE (-O-); b, ATEE (-O-); c, casein (-O-).

spectively. Thus, since assay of sfericase is more sensitive with ATNE than with other substrates, ATNE was used as substrate in subsequent experiments.

\section{Effects of SDS on hydrolysis of ATNE by sfericase and rabbit serum}

Rabbit serum itself exhibited ATNE hydrolytic activity. This endogenous activity was not identified in this work, but was probably due to an esterase. For measurement of ATNE hydrolytic activity of absorbed sfericase in rabbit serum it was necessary to inhibit this endogenous ATNE hydrolytic activity without affecting the activity of sfericase. Therefore, we tested the effects of several inhibitors of protease and esterase and of protein denaturants on the ATNE hydrolytic activities of sfericase and rabbit serum. Among the various substances tested, SDS was the most effective.

Figure 2 shows the effects of various concentrations of SDS on the ATNE hy-

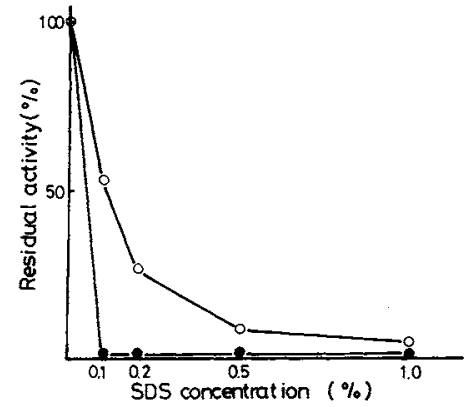

FIG. 2. Effects of Various Concentrations of SDS on the ATNE Hydrolytic Activities of Sfericase and Rabbit Serum.

Assays in the absence and presence of SDS were carried out as described in Materials and Methods. - $\mathrm{O}-$-, sfericase $(0.04 \mu \mathrm{g}) ;--$, rabbit serum $(0.01 \mathrm{ml})$.

drolytic activities of sfericase and control rabbit serum. At a final concentration of $0.1 \%$, SDS inhibited the activity of rabbit serum almost completely and that of sfericase about $50 \%$. At this concentration of SDS, the inhibition on sfericase was consistently about $50 \%$ over the enzyme concentration range tested, whereas the ATNE hydrolytic activity of up to $0.04 \mathrm{ml}$ of rabbit serum was completely inhibited. The absorbancy of ATNE hydrolytic activity of $0.1 \mathrm{ml}$ of rabbit serum was about 0.1 .

Effect of SDS on ATNE hydrolytic activity of sfericase in rabbit serum

Figure 3 shows the effect of SDS on the ATNE hydrolytic activity of sfericase added to rabbit serum. In the absence of SDS, the activities of the serum and added sfericase were additive. On addition of sfericase at a final concentration of $0.01,0.02$ or $0.04 \mu \mathrm{g}$ per $\mathrm{ml}$ to $0.1 \mathrm{ml}$ of rabbit serum without SDS, the hydrolytic activities were too high to be detected, the optical density being above 2.0. In the presence of $0.1 \%$ SDS the activities of the mixtures were measurable, since the endogenous activity of the serum was inhibited, and the activity depended only on the concentration of added sfericase. However, the values in these mixtures were higher than those in mixtures of the same amounts of sfericase 


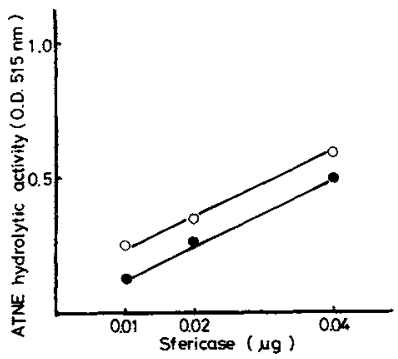

FIG. 3. Effect of SDS $(0.1 \%)$ on the ATNE Hydrolytic Activity of Sfericase in Rabbit Serum.

Assays in the absence and presence of rabbit serum were carried out as described in MATERIALS AND METHoDs. A final concentration of $0.1 \%$ SDS and $0.1 \mathrm{ml}$ of rabbit serum were used. --O-, ATNE hydrolytic activity of sfericase in the presence of SDS and rabbit serum; - - ATNE hydrolytic activity of sfericase in the presence of SDS.

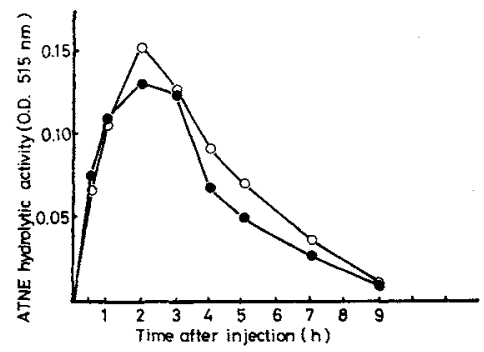

FIG. 4. Intestinal Absorption of Sfericase Injected Directly into the Intestine.

$200 \mathrm{mg}$ of sfericase was injected as described in Materials AND Methods. Blood samples were taken at the indicated times from the ear vein. The blood was allowed to clot and ATNE hydrolytic activity of the serum was estimated in the presence of SDS $(0.1 \%)$. $0.1 \mathrm{ml}$ of 10 -fold diluted serum was used in assays. - $\mathrm{O}-$ and - - experiments 1 and 2 .

and SDS without serum. This difference might be due to residual endogenous activity in the serum in the presence of SDS $(0.1 \%)$.

\section{Absorption of sfericase injected directly into the intestine}

Doses of $200 \mathrm{mg}$ of sfericase in $10 \mathrm{ml}$ of saline were injected into the intestine as described in the Materials and Methods. As shown in Fig. 4, the concentration of sfericase in the blood was maximal at $2 \mathrm{hr}$ after the injection. The percent absorptions after $2 \mathrm{hr}$ in

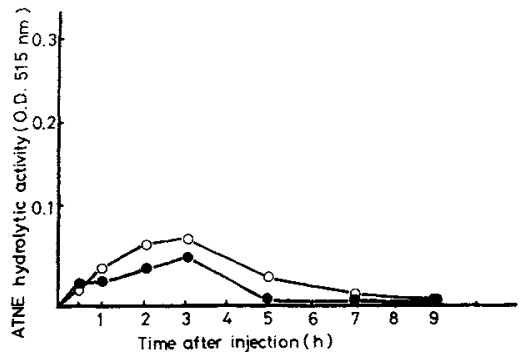

Fig. 5. Intestinal Absorption of Enteric-coated Particles of Sfericase.

Sfericase was administered orally as described in Materials and Methods. $0.1 \mathrm{ml}$ of rabbit serum was used in assays. - $\mathrm{O}-$ and - - experiments $I$ and 2.

two separate experiments were $0.07 \%$ and $0.06 \%$.

\section{Intestinal absorption of enteric-coated particles of sfericase}

Figure 5 shows the intestinal absorption of sfericase at various times after oral administration of $1 \mathrm{~g}$ of enteric-coated particles, calculated from the ATNE hydrolytic activity of the serum in the presence of $0.1 \%$ SDS. The concentration of sfericase was maximal after $3 \mathrm{hr}$ and the percent absorptions in two experiments were $0.003 \%$ and $0.002 \%$.

\section{DISCUSSION}

In this work we found that ATNE was the best substrate for sfericase. However, we found that ATNE was also hydrolyzed by another enzyme(s) present in rabbit serum. Thus for measurement of the amount of sfericase absorbed, it was necessary to dissociate the ATNE hydrolytic activity of rabbit serum from that of sfericase. Therefore, we tested the effects of various protease and esterase inhibitors and of denaturants on the ATNE hydrolytic activities of sfericase and rabbit serum. Results showed that $0.1 \%$ SDS inhibited all the endogenous ATNE hydrolytic activity of rabbit serum, but only about half that of sfericase. Therefore, we were able to demonstrate the intestinal absorption of sfericase by measuring ATNE hydrolytic activity in the presence of $0.1 \%$ SDS. 
The sfericase concentration in the blood was maximal at $2 \mathrm{hr}$ after direct injection of sfericase into the intestinal lumen (Fig. 4), and $3 \mathrm{hr}$ after oral administration of enteric-coated particles (Fig. 5). The percentage absorption from the latter was only one twentieth to one thirtieth of that of sfericase injected directly into the intestine, but the reason for this difference is unknown.

\section{REFERENCES}

1) B. Kabacoff, A. Wohiman, M. Umhey and S. Avakian, Nature (London), 199, 815 (1963).

2) G. J. Martin, R. L. Bogner and A. Edelman, Am, J. Pharmacy, 129, 336 (1957).

3) R. D. Smyth, R. M. Brennan and G. J. Martin, Am.
J. Pharmacy, 133, 294 (1961).

4) T. Murachi, Abstracts, 10th International Congress of Biochemistry, Hamburg, July 1976, p. 306.

5) A. L. Warshow, W. A. Walker and K. J. Isselbacher, Gastroenterology, 66, 987 (1974).

6) K. Katayama and T. Fujita, Biochim. Biophys. Acta, 288, 181 (1972).

7) M. Niinobe, Y. Hitomi and S. Fujii, J. Biochem., 87, 779 (1980).

8) K. Yoshida, H. Hidaka, S. Miyado, U. Shibata, K. Saito and Y. Yamada, Agric. Biol. Chem., 41, 745 (1977).

9) R. S. Roberts, J. Biol. Chem., 232, 285 (1958).

10) O. H. Lowry, N. J. Rosebrough, A. L. Farr and R. J. Randall, J. Biol. Chem., 193, 265 (1951).

11) H. Sumi and S. Fujii, J. Biochem., 75, 253 (1974).

12) W. F. Ganong, Review of Medical Physiology, 6th Edition (translated in Japanese by K. Matsuda et al.), 1973, p. 381. 